\title{
Criticismo retórico: teoría, aplicación y crítica
}

\author{
Rhetorical criticism: theory, Application and critics \\ criticismo retórico: teoria, aplicação e crítica
}

DOI: https://doi.org/10.21803/pensam.v17i21-1.267

Cristian Cardozo Mindiola https://orcid.org/0000-0001-7024-5263.

\section{¿Cómo citar este artículo?}

Cardozo, C. (2018). Criticismo retórico: Teoría, aplicación y crítica. Pensamiento Americano, $11(21), 90-99$.

\section{Resumen}

El presente artículo busca describir el enfoque hermenéutico conocido como "criticismo retorico", analizar sus presuposiciones, aplicar el enfoque a la carta de Filemón y por ultimo ofrecer una crítica del enfoque. Este estudio muestra que el criticismo retorico resulta ser una herramienta útil para la hermenéutica literaria ya que en reacción a los movimientos que colocan el significado del texto en la comunidad que lo crea, el criticismo retorico busca determinar las intenciones del autor y los elementos que él usó para hacer persuasivo su discurso.

Palabras Claves: Retórica, Filemón, Hermenéutica, Biblia, Historia.

\begin{abstract}
This article seeks to describe the hermeneutical approach known as "rhetorical criticism", analyze its presuppositions, apply the approach to the letter of Philemon and finally offer a critique of the approach. This study shows that rhetorical criticism turns out to be a useful tool for literary hermeneutics since in reaction to the movements that place the meaning of the text in the community that creates it, the rhetorical criticism seeks to determine the intentions of the author and the elements that he used to make his speech persuasive.
\end{abstract}

Keywords: Rhetoric, Philemon, Hermeneutics, Bible, History.

\footnotetext{
* El presente artículo es resultado del proyecto de investigación "Exegesis del Nuevo Testamento" aprobado por la Corporación Universitaria Adventista. El proyecto inició el 17 de Junio del 2018 y finalizó el 31 de Octubre del 2017 con número de proyecto PFT 001
} 


\section{Resumo}

O presente artigo busca descrever o enfoque hermenêutico conhecido como "criticismo retórico", analisar suas pressuposições, aplicar o enfoque à carta de Filemon e por último oferecer uma crítica a esse enfoque. Este estudo mostra que o criticismo retórico resulta ser uma ferramenta útil para a hermenêutica literária já que está em reação aos movimentos que colocam o significado do texto na comunidade que o cria. O criticismo retórico busca determinar as intenções do autor e os elementos que ele usou para fazer persuasivo o seu discurso.

Palavras chave: Retórica, Filemon, Hermenêutica, Bíblia, História.

\section{Perfil}

\section{Cristian Cardozo Mindiola}

Candidato doctoral en Nuevo testamento. de la Universidad Adventista del Plata, Libertador San Martín.

Profesor de Teología en la Corporación Universitaria Adventista (Medellín, Colombia). Es miembro del grupo "Investigaciones Teológicas Unac"; avalado por Colciencias. ccardozo@unac.edu.co 


\section{Introducción}

A partir de la segunda mitad del siglo XX, ocurrió un giro en las hermenéuticas con las cuales se abordaba el estudio del Nuevo Testamento, de la objetividad se saltó a la subjetividad, y en la tensión generada por estos dos polos aparece la retórica como elemento exegético (Baird, 2013). Oscilando entre estos dos puntos, el criticismo retórico abrió su camino como herramienta válida de interpretación mayormente en el campo de las epístolas paulinas. Aunque su aceptación en el campo de los estudios bíblicos ha sido positiva, aún es necesario reflexionar sobre sus implicaciones, validez, utilidad dentro de una cosmovisión conservadora de las escrituras, su aplicabilidad a textos entendidos comúnmente como no-retóricos, etc. (Kern, 1998). Por ello, es el propósito de este artículo describir el criticismo retórico como herramienta hermenéutica, aplicar la herramienta a un texto neotestamentario y evaluar la utilidad de esta herramienta en la interpretación bíblica.

\section{Teoría y Hermenéutica}

La retórica "es una disciplina o un arte o una ciencia que se plantea y emprende con fundamento el estudio de las estrategias que conducen a la realización de un discurso eficaz para convencer a quienes lo oigan, o sea, persuasivo" (Eire, 2001, p.42). El criticismo retórico es una herramienta exegética del método histórico-critico (criticismo bíblico) que consiste en la aplicación del análisis retorico al estudio del texto bíblico.

El criticismo retórico hace uso de la retórica antigua para el análisis de textos, entendiendo que es un fenómeno global pero que fue sistematizado en su mejor forma por los griegos, por lo tanto, aunque ciertas estructuras puedan tener nombres griegos estas pueden ser encontradas en otras culturas y lenguajes (Porter, Porter \& Olbricht, 2001). Esta afirmación tiene sus raíces en concebir el fenómeno retórico como universal en lugar de local.

El criticismo retórico pretende analizar el texto bíblico centrándose en el punto de vista del autor y cómo su discurso (sea oral o escrito) podría ser percibido por sus contemporáneos (Kennedy, 1984, p.4). El criticismo retorico analiza las estrategias que hacen un discurso efectivo, así, el criticismo retorico del Nuevo Testamento requiere que se tome a la Biblia en términos orales disminuyendo su carácter escrito (Apocalipsis 1:3). El criticismo retórico reconoce que la única forma de abordar la retórica antigua es a través de textos. Sin embargo, debe tenerse en cuenta que en el contexto cristiano el impacto retórico era diseñado para el aspecto oral antes que para el escrito.

Ahora bien, en tiempos contemporáneos existen dos tendencias en los estudios retóricos (Velardo, 2014), el movimiento conocido como "The New Rethoric" (Watson \& Hauser, 1994). Y el criticismo socio-retórico. El primero tiene como representantes a Chaim Perelman y Lucie Olbrechts-Tyteca (Perelman \& Olbrechts-Tyteca, 1969), mientras que, el segundo tiene como representante a Vernon K. Robbins (1996).

La aplicación del análisis retórico al Nuevo Testamento llegó por manos de Hans D. Betz quien en un artículo publicado por New Testament Studies (Betz, 1975) echó el fundamento que serviría como base para la publicación de su comentario unos años más tarde sobre Gálatas (Betz, 1979) desde una perspectiva retórica. Además de Betz, uno de los máximos exponentes en la aplicación del análisis retorico al Nuevo Testamento es George Kennedy (1980), quien en palabras

Pensamiento Americano Vol. 11 (22) • 2018 • Julio-Diciembre • Corporación Universitaria Americana • Barranquilla, Colombia • ISSN: $2027-2448$. 
de Walton "has provided a classicist's perspective to the development of the discipline" (Walton, 1995, p.229).

La aplicación del análisis retórico al Nuevo Testamento por manos de Betz y Kennedy está precedida por aplicaciones de estudios de retórica al Nuevo testamento por San Agustin de Hipona, Philip Melanchton, etc'. La novedad a partir de Betz es "the attempt rhetorically to analyze a pauline letter in its entirety and to understand the flow of thoughts and arguments within the framework of the entire structure of a letter" (Lampe \& Sampley, 2010, p. 4).

El análisis retórico del Nuevo Testamento inició en los estudios Paulinos, algunos han aplicado el método a los evangelios (Kennedy, 1984), sin embargo, su aplicabilidad² es cuestionable (Mitchell, 1993, p.14). A partir de la aparición de los estudios por Betz y Kennedy, la producción bibliográfica sobre el análisis retórico del Nuevo Testamento ha aumentado en grandes proporciones ${ }^{3}$.

Teniendo en cuenta esta breve descripción de la hermenéutica propuesta, se pueden evidenciar algunas presuposiciones de esta herramienta hermenéutica, las cuales se presentan a continuación: en primer lugar, la Biblia es un texto literario y debe ser estudiado e interpretado como tal. En segundo lugar, se asume el texto en su estado actual, toma su forma final y no se interesa por las fuentes usadas o la redacción de las mismas. Y por último, los lectores del cristianismo primitivo del mundo griego estaban familiarizados con la retórica sea por educación formal (Mack, 1990) o porque desarrollaron culturalmente preconcepciones acerca del discurso apropiado 4 .

En la siguiente sección se describirá la metodología usada por los proponentes del criticismo retorico para analizar los textos neotestamentarios.

\subsection{Metodología 5}

El primer paso necesario para el criticismo retórico es determinar la pericopa o unidad retórica. La unidad retórica debe tener un principio, medio y un fin. En la unidad retórica debe estar claro el inicio y la conclusión del mismo, por eso no se puede depender de las traducciones modernas sino buscar marcas de inclusio.

El segundo paso consiste en establecer la situación de la unidad retórica, esto es, la situación que motivó a la respuesta retórica por parte del orador. Analizar el lenguaje revela que está mediado por situaciones y contextos, el análisis de la situación de la unidad retórica permite establecer el factor que ha de condicionar el mensaje, verbigracia, el informe recibido por Pablo de la iglesia de Corinto y su respectiva respuesta. Se debe tener en cuen-

\footnotetext{
1 Para una historia de la aplicación del análisis retorico al Nuevo Testamento antes de Betz y Kennedy, ver, (Watson \& Hauser, 1994, pp. 101-107).

2 La aplicabilidad del análisis retórico como ha sido planteado por Betz y Kennedy creo que no encuentra lugar en los evangelios por dos razones: el contenido del evangelio y su propósito escapan de las estructuras retóricas greco-romanas y la formación o conocimiento de retórica por parte de los evangelistas parece improbable.

3 Para un status questionis del asunto, ver, (Lampe \& Sampley, 2010, pp. 25-119; Velardo, 2014, pp. 46-47).

4 Se presupone que los escritores estaban familiarizados con la retórica, tanto el emisor-receptor del discurso debían estar en el mismo plano lingüístico, Kennedy ve este escenario como totalmente plausible en el Nuevo Testamento debido a que la retórica estaba presente en todas las esferas de la vida civil, ver, (Kennedy, 1984, p. 10).

${ }^{5}$ La metodología presentada es una paráfrasis de lo propuesto por Kennedy en (Kennedy, 1984, pp. 33-38). Otras metodologías están disponibles. Sin embargo, la presentada en este ensayo es suficientemente sencilla para aquellos quienes comienzan en el análisis de la retórica de los cuales el autor del presente ensayo es el primero. Jewett abordo el estudio de 1 y 2 de Tesalonicenses desde una perspectiva retórica ecléctica, es decir, integró la retórica antigua con la "new rhetoric" y las teorías lingüísticas. Ver, (Jewett, 1986, pp. 63-67). Mitchell ha criticado tanto a Kennedy como a Jewett; a Kennedy debido a que su metodología está basada en manuales de retórica antigua pero no tiene en cuenta el fenómeno retorico. Mitchell critica a Jewett debido a su método ecléctico, ella argumenta que el análisis no depende de la retórica antigua, los nombres antiguos de los géneros retóricos se aplican como han sido definidos por la "New rhetoric", y además critica que hay baches metodológicos en el planteamiento de Jewett. El modelo de Mitchell se enmarca en el modelo seguido por Betz, este se caracteriza por la comparación del texto bíblico con las fuentes retoricas antiguas, no solo los manuales de retórica sino la literatura en general que evidencia la retórica en la práctica, esto permite evitar errores y confusiones metodológicas ya que elementos como los géneros retóricos han sido redefinidos en la actualidad y no reflejan en forma completa lo que se entendía por ellos en el tiempo antiguo, aunque ella no menosprecia la "New rhetoric" muestra sus precauciones metodológicas y opta por usar las categorías tradicionales. Ella también enfatiza que la aplicación de los géneros retóricos debe ser comprobado y no ser una suposición, es por esto que ella dedica un capítulo de su libro a analizar el género deliberativo con el fin de encontrar categorías propias para su posterior aplicación a 1 de Corintios. Para las críticas a los autores mencionados y la exposición de su metodología retórica, ver, (Mitchell, 1993, pp. 5-19).
} 
ta, además, analizar las personas, objetos, tiempo y espacio. Se debe tener en cuenta determinar el problema retórico que suele encontrarse en el proemio o en el comienzo de la prueba y condiciona el argumento retórico (Jewett, 1986).

Un tercer paso es determinar los géneros (species) retóricos que pueden ser judicial, deliberativo, o epidíctico. Cada género tiene sus propias características que permiten una identificación, sin embargo en un cuerpo pueden mezclarse dos géneros y debe decidirse cual tiene mayor preponderancia.

Luego de determinar el género se debe analizar la organización del material, es decir, divisiones y sus propósitos persuasivos así como los instrumentos de estilo.

En último lugar, luego de analizar en detalle el argumento retórico, evaluar si la unidad retórica como tal cumplió su propósito a la luz de la exigencia que la gestó.

\section{Aplicación hermenéutica}

En la presente sección se analizara la epístola a Filemón teniendo en cuenta la metodología sugerida arriba.

\subsection{Determinación de unidad retórica}

La unidad retorica para analizar será la epístola a Filemón en su totalidad ${ }^{6}$. El texto base para el análisis de la unidad retórica será el de NA28.

\subsection{Situación retórica}

\footnotetext{
6 La elección de la epístola a Filemón no es casualidad. El texto es una carta corta que permite aplicar el criticismo retorico de forma controlada.

7 Se han planteado diversas opciones con sus respectivas fortalezas y debilidades para resolver esta tensión, entre las más frecuentes encontramos: (1) Que Onésimo conoció a Pablo siendo un compañero en la prisión, sin embargo se objeta a esta posición la imposibilidad de Pablo compartiendo la misma celda con un esclavo. (2) Que Onésimo busco a Pablo para que intercediese en un problema entre él y Filemón, sin embargo, no se explica como un esclavo no cristiano acudiría a Pablo para resolver una disputa. (3) Que Onésimo huyo de Filemón, llego a Roma y por casualidad se encontró con Pablo quien casualmente era amigo íntimo de su antiguo señor. Esta última propuesta, carece de todo fundamento y permanece en la especulación. Una vez más el silencio es el mejor argumento. Para un resumen de las posturas, ver, (Dunn, 1996, p. 306).

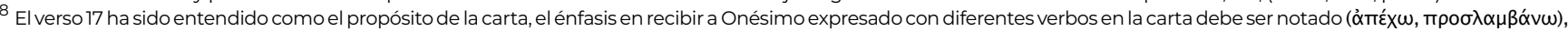
como Fitzmyer concluye "it is clear that Paul writes a personal and closely argued letter on behalf of Onesimus" (Fitzmyer, 2008, p. 23).
}

La tarea de identificar el género retórico de Filemón no es fácil, encontrar equivalencias entre la carta a Filemón y las características esperadas en determinado género retórico

Bajo este encabezado se analizara que situación motivo la escritura de la epístola a Filemotivo el discurso. Para entender adecuadamente la situación retórica que motivo a Pablo ${ }^{7}$, es necesario establecer que: Onésimo era un esclavo que pertenecía a un cristiano llasas. Onésimo había huido de Filemón (Melick, 2001), y de alguna forma contactó a Pablo y que Pablo se interesó por Onésimo, este fue obrero útil para Pablo, su estima hacia él era grande, a tal punto que le considera como "su propio corazón" (Dunn, 1996).

Con este contexto en mente, se puede deducir que la situación retórica se aproxima a lo siguiente: Sin conocer el porqué, Onésimo huyó convirtió en alguien útil para el ministerio de Pablo. Onésimo acompañaría a Tiquico en su misión de entregar la carta escrita por Pablo a era de esperarse el encuentro entre el esclavo y su maestro. Del texto podremos inferir que el temor de Pablo era que Onésimo no fuese decide escribir una carta con el propósito de convencer a Filemón de recibir a Onésimo y garantizar su libertad (Moo, 2008), quizás con el propósito de que Onésimo pudiese seguir sirviendo a Pablo.

\subsection{Género retórico}

Pensamiento Americano Vol. 11 (22) • 2018 · Julio-Diciembre • Corporación Universitaria Americana • Barranquilla, Colombia • ISSN: $2027-2448$ • http://publicaciones.americana.edu.co/index.php/pensamientoamericano/index 
como están definidos en los manuales de la antigüedad conlleva sorpresas. Aristóteles define 3 géneros o "especies" retóricas, que corresponden a clases de discursos. Los 3 géneros aristotélicos son: "el deliberativo, el judicial y el epidíctico" (Aristoteles \& Racionero, 2007, p. 194) . El criterio de división en el caso de Aristóteles es la audiencia puesto que esta es el fin último de los discursos. ${ }^{9}$ La comunidad puede ser pasiva (epidíctico) o activa, en el último caso emitirá juicios sobre lo futuro (deliberativo) o lo pasado (judicial) (Aristoteles \& Racionero, 2007, p. 193). El consejo y disuasión son propios del género deliberativo, la acusación o defensa propios del género judicial, el elogio y la censura del epidíctico (Aristoteles \& Racionero, 2007, p. 193). Los tiempos para la deliberación son el futuro, para la acción judicial el pasado y para el discurso epidíctico el presente (Aristoteles \& Racionero, 2007, pp. 194-195). El fin del discurso deliberativo es lo conveniente y lo perjudicial, para el judicial es lo justo y lo injusto, finalmente para el epidíctico es los bello y lo vergonzoso.

La distinción de 3 géneros retóricos tuvo sus detractores, Quintiliano menciona que:

"Verum et turn leviter est temptatum, cum apud Graecos quosdam turn apud Ciceronem in libris de Oratore, et nunc máximo temporum nostrorum auctore prope impulsum, ut non modo plura haec genera, sed paene innumera-bilia videantur."10 , sin embargo Quintiliano concluye que "The safest and most rational course seems to be to follow the authority of the majority."1 .

No obstante, teniendo en cuenta las dificultades encontradas por Quintiliano, es posi- ble identificar el género retórico dominante prestando atención a la intención del autor, como Kennedy lo explica:

Although many written discourses, such as epistles, combine features of deliberative, judicial, or epideictic rhetoric, it is often useful to consider the dominant rhetorical genre of a work in determining the intent of the author and the effect upon the audience in the original social situation (Kennedy, 1997, p.45).

Con el marco referencial provisto arriba, es necesario ahora determinar el género retórico de la carta a Filemón basados en la intención paulina, el papel de la audiencia y los elementos señalados por Aristóteles que caracterizan al género como tiempo de decisión, tema dominante, etc.

Un análisis de los criterios para la clasificación de un documento entre los géneros retóricos permite sugerir que Filemón pertenece a al género deliberativo por varias razones:

1. La comunidad emitirá una decisión

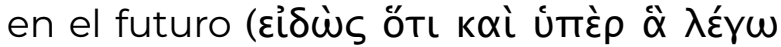

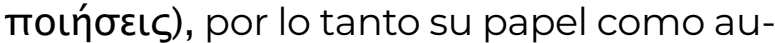
diencia es activo (Wallace, 1996, p.568).

2. La carta a Filemón es un consejo (en Quintiliano, "hortandi"), Pablo exhorta a Filemón en cuanto a su accionar con Onésimo (De vos, 2001)

3. El fin del género deliberativo es lo conveniente, Pablo escribe a Filemón señalándole que conviene recibir a Onésimo

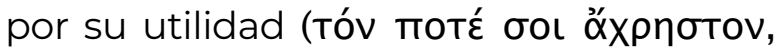

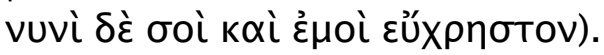

Con base a la evidencia presentada la Epístola a Filemón puede ser considerada como

9 Aristóteles, Ética a Nicomaco. III 7, 1115b23. “"todo se define por su fin»"

10 Quintiliano, Institutio Oratoria, III, IV, 2. Quintiliano dedica el capítulo 4 del libro 3 para analizar el tema de cuantos géneros retóricos existen, aunque el mismo reconoce la existencia de 3 géneros concluye que los 3 se yuxtaponen en cualquier discurso y que los elementos bajo los cuales se distinguen los tipos de discursos en realidad están presentes en todos, en palabras de Quintiliano: "the division thus made is easy and neat rather than true : for all three kinds rely on the mutual assistance of the other." 11 Quintiliano, Institutio Oratoria, III, IV, 12.

Pensamiento Americano Vol. 11 (22) · 2018 • Julio-Diciembre • Corporación Universitaria Americana • Barranquilla, Colombia • ISSN: 2027-2448 • http://publicaciones.americana.edu.co/index.php/pensamientoamericano/index 
representante del género deliberativo (Porter, 1997).

\subsection{Arreglos}

En esta sección se estudiara la forma en que está organizo el material con el fin de generar impacto retórico.

\subsubsection{Estructura}

Filemón

Prescripción epistolar

1:1-3 Saludo: Sitúa autor y audiencia.

Estructura retórica

\section{1:4-7 Exordium}

1:8-16 Prueba

1:17- 22 Peroratio

Conclusión epistolar

1:23-25 Salutaciones finales

\subsubsection{Exordium}

El propósito del exordium es preparar a la audiencia para que pueda estar atenta a lo que se ha de decir'2. Para ello, Pablo alaba las cualidades cristianas de Filemón para generar en él interés de conocer lo que sigue. $\mathrm{Pa}$ blo "то́́

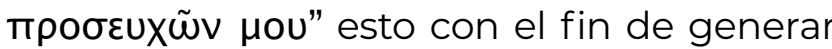
una buena impresión en Filemón ya que estar siempre en las oraciones del campeón de los apóstoles debía ser considerado un privilegio, de esta forma Pablo apela al adfectus.

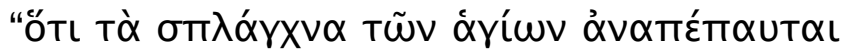

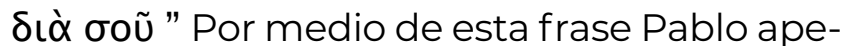
la al pathos de Filemón, busca demostrar el honor y las ventajas que él ha recibido por sus acciones basadas en el amor, este instrumento retórico apunta a generar interés en las ventajas que traería sobre Filemón si actúa como lo hizo en el pasado (Witherington, 2007).

En el exordium, Pablo establece los temas a los cuales recurrirá mientras su estrategia retórica se elucida. Entre estos elementos claves y recurrentes están el amor, la fe, la comunión, el bien, el corazón, etc (Church, 1978).

\subsubsection{Prueba}

Pablo continua su argumento afirmando que él tiene derecho cristiano para indicarle a Filemón lo que era su deber, sin embargo en lugar de apelar a su autoridad, pablo apela al ethos y pathos como sigue. Pablo ape-

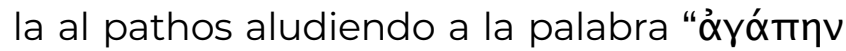
$\mu \tilde{\alpha} \lambda \lambda$ ov $\pi \alpha \rho \alpha \kappa \alpha \lambda \tilde{\omega}$ " de esta forma se busca que con base al amor que Filemón ya ha demostrado, la decisión que tome con respecto al pedido de Pablo sea basada en este mismo principio.

Pablo apela al ethos, aludiendo a su condición de prisionero y anciano, la intención retórica de esta apelación puede ser planteada así ¿Quién negaría algo a un prisionero por causa del evangelio?

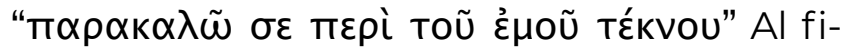
nal se presenta el pedido de Pablo, su preocupación es acerca de Onésimo, su nombre aparece en esta posición para preparar a Filemón.

"عúxрпбтоv" Pablo argumenta basado en la prueba de utilitas que Filemón debía aceptar a Onésimo ya que este ahora es útil para

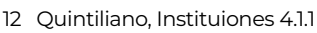


ambos.

En los versos 12-14, Pablo argumentando con base al motivo de honestas busca demostrar que al enviarle de vuelta a Onésimo, Filemón tiene la opción de recibirle y tratarle adecuadamente, Pablo siguiendo la oratoria toma el lugar de Onésimo para convencer a su audiencia.

Los versos 15-16 aunque sin ningún paralelo en la retórica de la época tiene una fuerza argumentativa clara, Onésimo debe ser recibido porque ese puede haber sido la voluntad del Señor. Se apela al motivo de la providentia.

\subsubsection{Peroratio}

“oũv" introduce el propósito, amplía su argumentación y deja la audiencia en un estado emocional para ganar su favor, Pablo hace esto aludiendo al pathos nuevamente de Filemón, es decir, para convencerlo alude a la efectividad de su comunión (vs6) y su certidumbre sobre la obediencia de Filemón que va más allá de lo requerido. Por medio de instrumentos retóricos en las siguientes líneas Pablo busca inclinar el corazón de Filemón hacia una buena decisión.

\subsection{Instrumentos del estilo}

Dentro de Filemón encontramos un silogis-

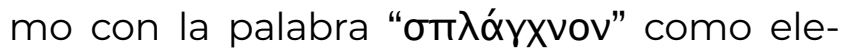
mento vinculador. La primera premisa está en verso 7, Filemón refresca el corazón de los santos, la segunda en el verso 12, Onésimo es el corazón de Pablo, la conclusión en el versículo 20, refrescar el corazón de Pablo es refrescar a Onésimo. Por medio de este silogismo Pablo procura persuadir a Filemón.

Dentro de la carta encontramos una antífrasis en el versículo 8, Pablo abandona el argumento de su autoridad para ordenar a File- món y su abandono drástico del argumento enfatiza el nuevo medio por el cual busca asirse del favor de Filemón, el amor.

Encontramos un conduplicatio del verbo "т $\alpha \rho \alpha \kappa \alpha \lambda \tilde{\omega}$ ", de esta forma Pablo realza su línea de argumentación que se basa no en la autoridad y la imposición sino en el amor y la voluntad de Filemón.

Encontramos también un anticipatioy praeteritio, de esta forma en el verso 18 Pablo no deja lugar a objeciones para que su pedido no se cumpla, así se anticipa y asegura el pago de alguna deuda con el fin de que su propósito sea cumplido, que Filemón reciba a Onésimo.

\section{Crítica}

Después de una aplicación del enfoque se ofrecen las siguientes críticas:

1. El criticismo retórico carece de criterios claros para determinar si un pasaje está construido en términos retóricos o no.

2. El criticismo retórico cuyo abordaje se basa en los manuales de retórica antigua tiende a forzar textos para que encajen en las categorías rígidas expuestas en la antigüedad.

3. El criticismo retórico histórico no incluye el fenómeno retórico como norma general al método usado para el análisis de los textos (Mitchell, 1993, p12).

4. Se podría aducir que al aplicar la retórica no hay realidad en los argumentos paulinos sino intención retórica solamente, sin embargo, la intención retórica paulina se distancia del sofismo y si la verdad se presenta en términos retóricos es para enfatizar su carácter. 


\section{Conclusión}

El análisis retórico ha demostrado ser una herramienta de sumo valor para el entendimiento del texto bíblico, puede ser aplicada desde una cosmovisión adventista siempre y cuando se adapte a las presuposiciones, el uso de esta herramienta en el campo de los estudios bíblicos proyecta estar en la agenda teológica al menos por algunos años, el análisis de la persuasión y la organización de los argumentos nos permite escuchar la voz de Dios con

\section{Referencias}

Aristóteles \& Racionero, Q. (2007). Retórica. Barcelona: RBA.

Baird, W. (2013). History of New Testament Research: Vol. 3: From C.H. Dodd to Hans Dieter Betz (Vol. 3). Minneapolis: Fortress Press.

Betz, H. D. (1975). The Literary Composition and Function of Paul's Letter to the Galatians. New Testament Studies, 21, 353-379.

Betz, H. D. (1979). Galatians: A Commentary on Paul's Letter to the Churches in Galatia. Philadelphia: Fortress Press.

Bruce, F. F. (1984). The Epistles to the Colossians, to Philemon, and to the Ephesians. Grand Rapids, MI: Eerdmans Publishing Company.

Church, F. F. (1978). Rhetorical structure and design in Paul's letter to Philemon. Harvard Theological Review, 71(2).

De vos, C. (2001). Once a slave, always a slave?: slavery, manumission and relational patterns in Paul's letter to Philemon.. Journal for the Study of the New Testament, 82, 89-105.

Dunn, J. (1996). The Epistles to the Colossians and to Philemon: A Commentary on the Greek Text. Grand Rapids, Ml: Eerdmans Publishing Company.

Eire, A. L. (2001). Los fundamentos de la Retórica. Bahía Blanca, Bs. As: Universidad Nacional del Sur.

Fitzmyer, J. A. (2008). The Letter to Philemon: A New Translation With Introduction and Commentary. New Haven, Conn: Yale University Press.

Jewett, R. (1986). The Thessalonian Correspondence: Pauline Rhetoric and Millenarian Piety. Philadelphia: Fortress Press. 
Kennedy, G. (1980). Classical Rhetoric and its Christian and Secular Tradition from Ancient to Modern Times. Chapel Hill: University of North Carolina Press.

Kennedy, G. (1984). New Testament Interpretation Through Rhetorical Criticism. Chapel Hill: University of North Carolina Press.

Kennedy, G. (1997). The Genres of Rhetoric. En S. Porter (Ed.), Handbook Of Classical Rhetoric In The Hellenistic Period, 330 B.C.-A.D. 400. Leiden: Brill.

Kern, P. H. (1998). Rhetoric and Galatians: assessing an approach to Paul's epistle. Cambridge, U.K.; New York: Cambridge University Press.

Lampe, P. \& Sampley, P. (2010). Paul and Rhetoric. New York: T\&T Clark.

Mack, B. L. (1990). Rhetoric and the New Testament. Minneapolis: Fortress Press.

Melick, R. (2001). Philippians, Colissians, Philemon (Vol. 32). Nashville, TN: Broadman \& Holman.

Mitchell, M. (1993). Paul and the Rhetoric of Reconciliation: An Exegetical Investigation of the Language and Composition of 7 Corinthians. Louisville, Ky: Westminster/John Knox Press.

Moo, D. J. (2008). The Letters to the Colossians and to Philemon, The Pillar New Testament commentary. Grand Rapids, MI: Eerdmans Publishing Company.

Perelman, C. \& Olbrechts-Tyteca, L. (1969). The New Rhetoric: A Treatise on Argumentation. Notre Dame, IN: University of Notre Dame Press.

Porter, S. (1997). Handbook of Classical Rhetoric in the Hellenistic Period, 330 B.C.-A.D. 400. Leiden: Brill.

Porter, S., Porter, S., \& Olbricht, T. (2001). The Theoretical Justification for Application of Rhetorical Categories to Pauline Epistolary Literature. En Rhetoric and the New Testament: Essays from the1992 Heidelberg
Conference. Sheffield: Sheffield Academic Press.

Robbins, V. (1996). Exploring the Texture of Texts: A Guide to Socio-Rhetorical Interpretation. Valley Forge, PA: Trinity Press.

Sanders, L. (2004). Equality and a request for the manumission of Onesimus. Restoration Quarterly, 46(2).

Velardo, L. (2014). ¿Rétor o epistológrafo?: una reflexión sobre el análisis Retórico del epistolario paulino. DavarLogos, XIII, 42-44.

Wallace, D. B. (1996). Greek Grammar Beyond the Basics: An Exegetical Syntax of the New Testament. Grand Rapids, MI: Zondervan.

Walton, S. (1995). What has Aristotle to do with Paul? Rhetorical criticism and7 Thessalonians. Tyndale Bulletin, 46.

Watson, D., \& Hauser, A. (1994). Rhetorical Criticism of the Bible: A Comprehensive Bibliography with Notes on History and Method. Leiden: Brill.

Witherington, B. I. (2007). The Letters to Philemon, the Colossians, and the Ephesians: A Socio-Rhetorical Commentary on the Captivity Epistles. Grand Rapids, MI: Eerdmans Publishing Company.

2018, Vol. 11(22) 90-99 @The Author(s) 2018 Reprints and permission: www.americana.edu.co https://www.coruniamericana.edu.co/publicaciones/ojs/index.php/pensamientoamericano/index 